\title{
Avaliação das principais causas de perdas pós-colheita de hortaliças comercializadas em Santarém, Pará
}

\section{Evaluation of the main causes of post-harvest losses of vegetables sold in Santarém, Pará state}

\author{
Antonia Mirian Nogueira de Moura Guerra ${ }^{1 *}$, Ana Cecília Moura Costa ${ }^{2}$, Júlia Batista Azevedo Ferreira ${ }^{2}$, Paula Raniele \\ Freitas Tavares ${ }^{2}$, Thaís Silva Vieira ${ }^{2}$, Aline Carla de Medeiros ${ }^{3}$
}

Resumo: As hortaliças estão sujeitas a diversos tipos de danos após a colheita, ocasionados por condições inadequadas de manuseio, armazenagem, doenças e injúrias mecânicas. Este trabalho teve como objetivo levantar informações sobre as principais causas de perdas pós-colheita em pimentões, batatas e cebolas comercializadas nas feiras e supermercados de Santarém, Pará. O trabalho foi conduzido no comércio varejista, supermercados, Feira da Cohab, Feira do Aeroporto Velho e Mercadão 2000. Os danos nas hortaliças foram avaliados e classificados em: danos fisiológicos, microbiológicos e mecânicos. Em todos os locais avaliados todas as hortaliças apresentaram algum dano, que foi atribuído como responsáveis pelas perdas de forma direta ou indireta. Nas cebolas os principais danos foram: talo grosso, bulbos mal formados, flácidos, descoloridos e brotados. Todos os pimentões avaliados apresentaram formato retangular e cor verde, os principais danos encontrados foram: frutos amassados, apodrecidos, queimados, atacados por insetos, feridos, murchos, com rachaduras e malformados. Os tubérculos apresentaram-se com cortes superficiais não diferiu entre os diferentes locais, porém destacaram-se as amassaduras, esfoladuras, esverdeamento, má formação e murcha nos comercializados nas feiras, enquanto que nos supermercados os danos mais presentes foram os cortes profundos e brotados. Estes resultados revelam a necessidade de investimento na estruturação dos mercados varejistas para que possibilitem a diminuição das indesejáveis perdas e prejuízos financeiros na comercialização de hortaliças.

\section{Palavras-chave: Capsicum annuum; Allium cepa; Solanum tuberosum}

\begin{abstract}
Vegetables are subject to various types of damage after harvest due to inadequate handling and storage, disease and mechanical injury. The objective of this work was to carry out a survey of the main causes of post-harvest losses in peppers, potatoes and onions marketed in the fairs and supermarkets of Santarém, Pará state. The work was conducted in the retail trade, in the following places: Supermarket, Cohab Fair, Old Airport Fair and Mercadão 2000. The damages in the vegetables were evaluated and classified in: physiological, microbiological and mechanical damages. In all the evaluated places all the vegetables presented some damage, that was attributed like responsible of the losses of direct or indirect form. On the onions the main damages were: thick stalk, poorly formed bulbs, flaccid, discolored and sprouted. All the evaluated peppers presented rectangular and green color, the main damages were: crushed, rotted, skinned, burned and attacked by insects, wounded, withered, cracked and poorly formed. Tubers with superficial cuts did not differ among the different locations, but the most frequent damages were the deep cuts and sprouts. These results reveal the need for investment in the structuring of the retail markets to promote the reduction of undesirable losses and financial losses.
\end{abstract}

Key words: Capsicum annuum; Allium cepa; Solanum tuberosum

\footnotetext{
*Autor para correspondência

Recebido para publicação em 15/10/2016; aprovado em 10/01/2017

${ }^{1}$ Universidade Federal do Oeste da Bahia, Centro Multidisciplinar Campus de Barra, Av. 23 de Agosto s/nº, Bairro Assunção, CEP: 47100-000, Barra (BA). Email: mirianagronoma@ hotmail.com

${ }^{2}$ Universidade Federal do Oeste do Pará, Instituto de Biodiversidade e Florestas (Tapajó), Rua Vera Paz, s/nº, Bairro Salé, CEP:68035-110, Santarém (PA).

${ }^{3}$ Universidade Federal de Campina Grande, CCTA, Rua Jairo Vieira Feitosa, 1770 - Pereiros, Pombal - PB.
} 


\section{INTRODUÇÃO}

As frutas e hortaliças continuam vivas depois da colheita, mantendo ativos os processos biológicos vitais, portanto, continuam tendo um alto teor de água em sua composição química, tornando-as alimentos altamente perecíveis (LUENGO et al., 2007). Dessa forma, são fundamentais para aumentar o tempo de conservação e reduzir as perdas pós-colheita, que se conheçam e se utilizem práticas adequadas de manuseio durante as fases de colheita, armazenamento, comercialização e consumo (RINALDI, 2011).

Embora exista uma grande diversidade e disponibilidade de produtos hortícolas no mercado, sua alta perecibilidade dificulta a comercialização e o manuseio em condições ambientais inadequadas aceleram a perda de qualidade (CENCI, 2006).

Um dos maiores problemas da cadeia produtiva está no nível de perdas pós-colheita, que estão aliadas a fatores como injúrias mecânicas causadas por embalagens inadequadas e manuseios incorretos que começam na propriedade rural, na colheita do produto, na classificação e seleção das hortaliças, indo até aos consumidores intermediários e finais. Estes fatores são responsáveis pelas elevadas perdas no processo de comercialização e, consequentemente, por grande parte das consideráveis distâncias entre os preços de compra e os de venda dos produtos hortícolas (CHITARRA; CHITARRA, 2005). Soares (2009) acrescenta que o transporte inadequado, ausência da cadeia do frio, a comercialização a granel, desconhecimento de técnicas de manuseio pré e pós-colheita, o excesso de "toque" pelos consumidores nos produtos, acúmulo de produtos nas gôndolas de exposição de varejo como agravantes às perdas de hortaliças. Aliado a todos estes fatores, as altas temperaturas aumentam a velocidade das reações bioquímicas, dessa forma, o produto murcha e estraga mais rapidamente, o que reduz a sua vida útil (LUENGO et al., 2007).

Estudos realizados revelam que, entre a colheita e a chegada à mesa do consumidor, no Brasil, os níveis médios de perdas são de 35 a $40 \%$, enquanto em outros países, como nos Estados Unidos, não passam de $10 \%$ (VILELA et al., 2003a; VILELA et al., 2003b; MELO; VILELA, 2007; LUENGO; CALBO, 2011; RINALDI, 2011).

Santarém possui uma população estimada no ano de 2015 de 292.520 habitantes (IBGE, 2010) e é considerado o principal município do Oeste do Pará, onde a agropecuária baseada na produção de mandioca, de grãos (soja e milho), bovinocultura (carne), avicultura (pequena escala) e agricultura familiar. A produção de hortaliças é modesta, e o fornecimento para atender a população vem de estados das regiões Sudeste, Nordeste e Centro-Oeste através de transporte rodoviário por estradas em péssimo estado de conservação, o que leva alguns dias para a chegada dos produtos, favorecendo o aumento dos danos e das perdas.

Comumente a comercialização de hortaliças nas cidades brasileiras interioranas é pouco organizada e deficiente de informações, além de dependerem do fluxo de fornecimento das grandes centrais de abastecimento. Escassas são as informações na literatura acerca de perdas pós-colheita em hortaliças nas cidades interioranas, ficando esses dados restritos apenas as grandes centrais de abastecimento das regiões Sul e Sudeste. Neste ínterim, objetivou-se levantar informações acerca das causas de perdas pós-colheita em hortaliças (batata, cebola e pimentão) comercializadas nas feiras e supermercados de Santarém, Pará, propondo medidas que minimizem os desperdícios destas hortaliças.

\section{MATERIAL E MÉTODOS}

O trabalho foi conduzido no comércio varejista de Santarém, Pará $\left(02^{\circ} 24^{\prime} 52^{\prime \prime} \mathrm{S}\right.$ de latitude; 54² $42^{\prime} 36^{\prime \prime}$ W e 152 $\mathrm{m}$ de altitude), a temperatura média anual é de $25{ }^{\circ} \mathrm{C}$ e umidade relativa do ar de $86 \%$ (SILVA; NECHET, 2006), sendo os locais avaliados: supermercados, Feira da Cohab, Feira do Aeroporto Velho e Mercadão 2000.

As avaliações foram realizadas antes da exposição das hortaliças para a comercialização. Foram avaliadas amostras de qualidade inicial com a finalidade de identificar os possíveis danos que representam fontes potenciais de perdas, referentes à hortaliça comprada pelo comerciante, que ainda não foi levada para a área de vendas e nem distribuída para o consumidor. Os danos nas hortaliças foram avaliados e classificados em: danos fisiológicos (aqueles que ocorreram devido alguma interferência ou dano ao metabolismo da planta, ocorrendo tanto em condições de campo quanto durante o armazenamento); danos microbiológicos (foram aqueles ocasionados por microrganismos e insetos originários do campo ou do processo de embalagem e armazenamento) e danos mecânicos (tratou-se daqueles que ocorrem devido a alguma interferência a nível de campo ou manuseio inadequado, ocorrendo tanto em condições de campo ou mesmo durante o beneficiamento, armazenamento e comercialização).

A técnica amostral utilizada foi a de amostragem de parte do estoque total. Foi tomada uma amostra de quatro caixas de $20 \mathrm{~kg}$ de cada hortaliça para avaliações e pesagens. Foram avaliados as hortaliças cebola, batata e pimentão.

\section{Pimentão (Capsicum annuum L.)}

$\mathrm{Na}$ amostra foram caracterizados os atributos de interesse para o grupo (de acordo com o formato do fruto: retangular, cônico e quadrado), subgrupo (conforme a coloração do fruto: vermelho, amarelo, laranja, verde, creme e roxo) (SOUZA, 2004), danos mecânicos, fisiológicos e microbiológicos (LANA et al., 2006).

Os danos fisiológicos foram murcho (flacidez, fruto sem turgescência, enrugado ou sem brilho), queimado (fruto que apresenta área descolorida e/ou necrosada, provocada pela ação do sol e/ou geada), dano não cicatrizado (ferida ou lesão não cicatrizada de origem diversa), manchado (alteração na coloração normal do fruto não proveniente da evolução do estágio de maturação do mesmo), deformado (desvio acentuado na forma característica da cultivar), estrias (fenda superficial na cutícula, de natureza não progressiva), ferimento cicatrizado (ferida ou lesão cicatrizada de origem diversa). Danos mecânicos: ferimentos (cortes profundos ou superficiais), esfoladuras (frutos que apresentam exposição dos tecidos internos por falta de pele), amassados ("estouro" ou rachadura do fruto), dano por geada (fruto que apresenta perda de consistência e zonas necrosadas provocadas pela ação da geada). Danos microbiológicos: apodrecimento (dano patológico e/ou fisiológico que implique em qualquer grau de decomposição, desintegração e fermentação dos tecidos), ataque por insetos (frutos com sintomas de ataque por insetos), dano mecânico + insetos (frutos com danos 
mecânicos e com sintomas de ataque de insetos) (LANA et al., 2006). Sem danos: frutos que não apresentarem quaisquer dos danos descritos anteriormente.

A proporção de cada um destes itens foi expressa em \% (massa de frutos com dano em relação à massa total da caixa).

\section{Cebola (Allium cepa L.)}

As porções foram pesadas separadamente e a proporção calculada em \% da massa total da caixa. Os bulbos foram separados de acordo com os danos descritos a conforme Souza (2004), e sendo enquadrado em uma única categoria.

Danos fisiológicos foram talo grosso, brotado (quando o bulbo apresenta emissão do broto visível acima do colo), colo malformado (formação incompleta do colo do bulbo), flacidez (falta de turgescência, ausência da rigidez normal do bulbo), descoloração (desvio parcial ou total na cor característica da cultivar, incluindo o esverdeamento), deformado (bulbo que apresenta formato diferente do típico da cultivar). Os danos microbiológicos foram classificados em podridão (dano patológico e/ou fisiológico que implique em qualquer grau de decomposição, desintegração ou fermentação dos tecidos), mancha negra (área enegrecida em virtude do ataque de fungos nas catáfilas externas ou no colo do bulbo), mofado (bulbo que apresenta fungo nas catáfilas externas). Como danos mecânicos foram consideradas as lesões (de origem mecânica, observada nas catáfilas do bulbo), cortes (superiores $1 \mathrm{~cm}$ de profundidade, provenientes do manuseio inadequado durante a colheita e nas etapas de pós-colheita), amassaduras (originárias tanto durante o processo de colheita quanto no armazenamento e transporte devido a compressão imposta pelo enfardamento), esfoladuras (lesões mais profundas no bulbo originárias durante os processos de colheita, lavagem, seleção, embalagem e transporte). Sem danos: bulbos que não apresentarem quaisquer dos danos descritos anteriormente.

A proporção de cada um destes itens foi expressa em $\%$ (massa de bulbos com dano em relação à massa total da caixa).

\section{Batata (Solanum tuberosum L.)}

Os tubérculos foram classificados quanto aos danos mecânicos, fisiológicos e microbiológicos presentes na massa total da caixa (SOUZA, 2004).

Foram considerados como danos fisiológicos: murchos, esverdeados (quando a área afetada alcançar mais de $5 \%$ da superfície do tubérculo e profundidade em mais de $3 \mathrm{~mm}$ da polpa), coração negro (mancha de conformação irregular e de coloração cinza que ocorre no interior do tubérculo), brotado ou embonecado (crescimento secundário e desuniforme do tubérculo com brotos), mancha chocolate (mancha de cor marrom, semelhante a do chocolate que se observa na parte interna do tubérculo), vitrificação (tubérculo que apresentava a polpa fibrosa ou cristalizada), mal formado (desuniformidade severa de desenvolvimento do tubérculo com extremos pronunciados), coração oco (cavidade interna, causada por crescimento excessivamente rápido do tubérculo). Os danos microbiológicos foram a podridão seca (necrose nos tecidos, de aspecto desidratado ou mumificado), podridão úmida (necrose dos tecidos resultando em aspecto aquoso, mole e odor fétido), rizoctonia (agregados negros (escleródios) aderidos à pele do tubérculo causado pelo fungo
Rhizoctonia solani, superior a 5\% da superfície do tubérculo), perfurações e broca alfinete (ataque por insetos de solo fazem furos nos tubérculos que ficam com aparência de alfinetados). Foram classificados como danos mecânicos: cortes superficiais (a lesão não afetar mais de 10\% do tubérculo), cortes profundos (quando a lesão persiste após a remoção de 3 $\mathrm{mm}$ do tecido e produz uma perda superior a $5 \%$ em peso para se eliminar o dano), esfoladuras (tubérculo que apresenta exposição dos tecidos internos por falta de pele, sendo originados quando a cura é realizada de maneira inadequada) e rachaduras e amassados ("estouro" ou rachadura do tubérculo causada por crescimento excessivo relacionado a causas ambientais, como falta ou excesso de água, ou mesmo atividades mecanizadas) (SOUZA, 2004). Sem danos: tubérculos que não apresentarem quaisquer dos danos descritos anteriormente.

A proporção de cada um destes itens foi expressa em $\%$ (massa de tubérculos com dano em relação à massa total da caixa).

Adotou-se o delineamento inteiramente casualizado com quatro tratamentos (cada estabelecimento foi considerada como um tratamento). Foram comparados entre si os locais de coleta de dados: 1) supermercados; 2) Feira da Cohab; 3) Feira do Aeroporto Velho e, 4) Mercadão 2000. Os dados foram submetidos à análise de variância e as médias dos locais foram comparadas entre si pelo teste de Tukey a 5\% de probabilidade.

\section{RESULTADOS E DISCUSSÃO}

Em todos os locais avaliados neste estudo foi observada a presença de danos, aos quais se atribui como responsáveis pelas perdas de forma direta ou indireta. Conforme relatos dos proprietários dos estabelecimentos comerciais, verificou-se que a cebola e a batata foram adquiridas exclusivamente de produtores externos ao Estado, principalmente nas CEASAs de São Paulo (SP), de Belo Horizonte (MG) e de Goiânia (GO), enquanto que para o pimentão, parte foi oriundo das CEASAs citadas, e parte foi obtida dos produtores locais que possuem contratos de comercialização com o supermercado. Essa forma de abastecimento apresenta grandes problemas de sazonalidade de oferta e de preço, bem como de qualidade, pois o transporte, exclusivamente rodoviário, contribui para o incremento nos danos durante o deslocamento até Santarém.

Em todos os locais avaliados observou-se algum tipo de dano que poderia vir a comprometer a qualidade dos tubérculos, sendo que nas feiras (de 50 a 55\%) houve maior incidência em relação ao supermercado (45\%). Os tubérculos comercializados nas feiras não diferiram entre si para os danos mecânicos, porém na feira do Aeroporto Velho ocorreu uma tendência de maior incidência destes. Os danos fisiológicos e microbiológicos foram mais presentes naqueles expostos no supermercado em relação às demais (Tabela 1). Tofanelli et al. (2009) observaram perdas de 9,9\% nas batatas comercializadas na rede varejista de Mineiros (GO), esse menor volume foi atribuído a maior vida pós-colheita desta tuberosa. Por outro lado, Almeida et al. (2012b) constataram que na rede varejista de Areia - PB as perdas devido aos danos em batata alcançaram 29,08\%. A alta incidência de danos aqui encontrados se deve a aquisição, muitas vezes um produto de qualidade inferior, bem como ao longo transporte 
rodoviário em condições inadequadas que levam a redução da qualidade final.

Tabela 1. Classificação dos tipos de danos encontrados em tubérculos de batata comercializados na rede de comércio varejista de Santarém, Pará.

\begin{tabular}{|c|c|c|c|c|c|c|}
\hline \multirow[b]{2}{*}{ Variáveis } & \multicolumn{4}{|c|}{ Locais avaliados } & \multirow[b]{2}{*}{ DMS } & \multirow[b]{2}{*}{ Erro } \\
\hline & $\begin{array}{l}\text { Feira da } \\
\text { Cohab }\end{array}$ & $\begin{array}{c}\text { Feira do Mercadão } \\
2000\end{array}$ & $\begin{array}{c}\text { Feira do Aeroporto } \\
\text { Velho }\end{array}$ & $\begin{array}{c}\text { Rede de } \\
\text { Supermercados }\end{array}$ & & \\
\hline \multicolumn{7}{|c|}{ Ausência e presença de danos (\%) } \\
\hline Com danos & $50,00 \mathrm{a}$ & $52,00 \mathrm{a}$ & $55,00 \mathrm{a}$ & $45,00 \mathrm{~b}$ & 6,00 & 2,60 \\
\hline Sem danos & $50,00 \mathrm{~b}$ & $48,00 \mathrm{~b}$ & $45,00 \mathrm{~b}$ & $55,00 \mathrm{a}$ & 4,50 & 2,90 \\
\hline \multicolumn{7}{|c|}{ Tipos de Danos $(\%)$} \\
\hline Mecânicos & $56,50 \mathrm{a}$ & $65,00 \mathrm{a}$ & $71,75 \mathrm{a}$ & $17,50 \mathrm{~b}$ & 26,23 & 6,24 \\
\hline Fisiológicos & $28,00 \mathrm{ab}$ & $18,75 b c$ & $5,00 \mathrm{c}$ & $40,00 \mathrm{a}$ & 18,94 & 4,51 \\
\hline Microbiológicos & $15,50 \mathrm{~b}$ & $16,25 b$ & $23,25 b$ & $42,50 \mathrm{a}$ & 13,54 & 3,22 \\
\hline \multicolumn{7}{|c|}{ Danos Mecânicos (\%) } \\
\hline Amassados/rachados & $32,50 \mathrm{a}$ & $19,75 \mathrm{a}$ & $32,00 \mathrm{a}$ & $2,75 b$ & 12,98 & 3,09 \\
\hline Cortes profundos & $17,50 \mathrm{~b}$ & $25,75 b$ & $18,00 \mathrm{~b}$ & $48,50 \mathrm{a}$ & 13,37 & 3,18 \\
\hline Esfoladuras & $21,75 \mathrm{a}$ & $30,25 \mathrm{a}$ & $22,25 \mathrm{a}$ & $23,75 b$ & 10,86 & 2,58 \\
\hline Cortes superficiais & $28,25 \mathrm{a}$ & $24,25 \mathrm{a}$ & $27,75 \mathrm{a}$ & $24,75 \mathrm{a}$ & 11,02 & 2,62 \\
\hline \multicolumn{7}{|c|}{ Danos Fisiológicos (\%) } \\
\hline Esverdeado & $55,50 \mathrm{a}$ & $53,70 \mathrm{a}$ & $46,50 \mathrm{a}$ & $38,25 a$ & 10,75 & 2,55 \\
\hline Mal formado & $19,00 \mathrm{a}$ & $17,55 \mathrm{a}$ & $23,75 \mathrm{a}$ & $20,75 a$ & 11,37 & 2,70 \\
\hline Murchas & $16,50 \mathrm{a}$ & $14,75 \mathrm{a}$ & $15,25 \mathrm{a}$ & $5,00 \mathrm{a}$ & 11,73 & 2,79 \\
\hline Brotado/embonecados & $9,00 \mathrm{~b}$ & $14,00 \mathrm{~b}$ & $14,50 \mathrm{~b}$ & $36,00 \mathrm{a}$ & 9,45 & 2,25 \\
\hline \multicolumn{7}{|c|}{ Danos Microbiológicos (\%) } \\
\hline Podridão úmida & $33,00 \mathrm{a}$ & $64,50 \mathrm{a}$ & $51,50 \mathrm{a}$ & $67,00 \mathrm{a}$ & 34,29 & 8,16 \\
\hline Perfuração por brocas & $67,00 \mathrm{a}$ & $35,50 \mathrm{a}$ & $48,50 \mathrm{a}$ & $33,00 \mathrm{a}$ & 48,86 & 11,63 \\
\hline
\end{tabular}

Médias na linha seguidas de mesma letra minúscula não diferem entre si pelo teste de Tukey a 5\% de probabilidade. DMS: diferença mínima significativa.

A presença de tubérculos com cortes superficiais não diferiu entre os diferentes locais, porém destacaram-se as amassaduras, esfoladuras, esverdeamento, má formação e murcha nos tubérculos comercializados nas feiras, enquanto que no supermercado os danos mais presentes foram os cortes profundos e brotados (Tabela 1). Luengo et. al. (2003) mensionam que os danos mecânicos, além de prejudicar a aparência do produto diretamente, diminuindo o seu valor comercial, constituem-se na principal via de penetração de agentes patogênicos, que causam deterioração e perda do alimento. Quando os tubérculos são expostos à luz, passam por um processo de esverdeamento, resultante da síntese da clorofila (FERNANDES et al., 2011). O manuseio excessivo durante as etapas de colheita, lavagem e beneficiamento, além de uma cura mal feita são responsáveis pela maior incidência de cortes na superfície dos tubérculos. Além da carga de danos que já vem das etapas de produção e beneficiamento, a longa viagem entre os centros de distribuição e a cidade de Santarém, através de rodovias em péssimo estado de conservação, associada com a ausência de climatização durante o trajeto, são agravantes para intensificar os danos.

Quanto aos danos microbiológicos, não houve diferença entre os locais analisados, todavia, na Feira da Cohab houve maior incidência de tubérculos perfurados por brocas, enquanto que maior presença de batatas com podridão úmida foi observada na Feira do Mercadão 2000 e Supermercado (Tabela 1). Almeida et al. (2012b) constataram que os agentes fitopatológicos foram os responsáveis pelas maiores perdas em batatas em Areia (PB), onde as doenças ocasionaram diversas interferências tanto nos ambientes de produção quanto naqueles destinados ao escoamento e à comercialização de batatas denotando a baixa qualidade e quantidade.
Os danos mecânicos oriundos do processo produtivo são uma janela que favorece o ataque por patógenos, uma vez que os comerciantes não utilizam de refrigeração para o armazenamento, e a mercadoria que não é vendida, retorna para locais de armazenamento para ser comercializada no outro dia, e esse processo de exposição, recolhimento, transporte, armazenamento e nova exposição, contribuem para aumento de danos mecânicos, e as condições climáticas locais favorecem a proliferação de microrganismos.

Em todas as cebolas avaliadas foi constatado algum tipo de dano, e no supermercado houve maior incidência destes em relação as feiras $(27,00 \%)$. Tofanelli et al. (2009) encontram perdas de aproximadamente $10 \%$ em cebolas comercializadas no município de Mineiros (GO), e boa parte destas foram atribuídas aos danos que vem do campo. Em trabalho de identificação de sistemas de produção de cebola nos principais estados produtores, Vilela et al. (2003b) constataram níveis médios de perdas de $30 \%$, resultantes de descarte do produto no processo de classificação, por não atender aos padrões de qualidade exigidos pelo mercado, o que mostra uma consonância com os dados obtidos neste estudo.

Bulbos com talo grosso e mal formados foram mais frequentes no Supermercado, os flácidos foram mais presentes na Feira da Cohab, os descoloridos estavam em maior quantidade na Feira do Mercadão 2000 e a alta incidência de brotados foi exceção apenas no Supermercado. Observou-se uma maior quantidade de danos mecânicos na Feira do Mercadão 2000, de danos fisiológicos na Feira do Mercadã0 2000 e Feira da Cohab, danos microbiológicos no Supermercado e Feira da Cohab. No supermercado foi constatado a maior incidência de todos os tipos de danos mecânicos. Não houve diferença estatística entre os locais 
para podridão e bulbos mofados, no entanto, na Feira do Mercadão 2000 observou-se uma tendência maior para ocorrência de podridões, enquanto que bulbos mofados destacaram-se nas Feiras da Cohab e do Aeroporto Velho (Tabela 2). Os danos mecânicos e fisiológicos em si não inviabilizam a comercialização, mas, a incidência de injúrias mecânicas é uma das causas mais importantes de perdas póscolheita porque afeta diretamente a aparência do produto e acelera diversos processos fisiológicos, como a desidratação e a respiração, levando ao murchamento e, também, pode favorecer o desenvolvimento de microrganismo, levando à podridão.

Tabela 2. Classificação dos tipos de danos encontrados em bulbos de cebola comercializados na rede de comércio varejista de Santarém. Pará

\begin{tabular}{|c|c|c|c|c|c|c|}
\hline \multirow[b]{2}{*}{ Variáveis } & \multicolumn{4}{|c|}{ Locais avaliados } & \multirow[b]{2}{*}{ DMS } & \multirow[b]{2}{*}{ Erro } \\
\hline & $\begin{array}{l}\text { Feira da } \\
\text { Cohab }\end{array}$ & $\begin{array}{c}\text { Feira do Mercadão } \\
2000\end{array}$ & $\begin{array}{c}\text { Feira do Aeroporto } \\
\text { Velho }\end{array}$ & $\begin{array}{c}\text { Rede de } \\
\text { Supermercados }\end{array}$ & & \\
\hline \multicolumn{7}{|c|}{ Ausência e presença de danos (\%) } \\
\hline Sem danos & $78,00 \mathrm{~b}$ & $76,00 \mathrm{~b}$ & $74,00 \mathrm{~b}$ & $83,00 \mathrm{a}$ & 7,00 & 3,80 \\
\hline Com danos & $22,00 \mathrm{a}$ & $24,00 \mathrm{a}$ & $26,00 \mathrm{a}$ & $27,00 \mathrm{a}$ & 7,90 & 1,90 \\
\hline \multicolumn{7}{|c|}{ Tipos de Danos (\%) } \\
\hline Mecânicos & $25,25 b$ & $46,50 \mathrm{a}$ & $31,00 \mathrm{~b}$ & $32,50 \mathrm{ab}$ & 15,32 & 3,64 \\
\hline Fisiológicos & $32,00 \mathrm{a}$ & $33,00 \mathrm{a}$ & $29,75 a$ & $21,00 \mathrm{a}$ & 12,28 & 2,92 \\
\hline Microbiológicos & $42,50 \mathrm{a}$ & $20,50 \mathrm{~b}$ & $37,50 \mathrm{a}$ & $46,50 \mathrm{a}$ & 14,29 & 3,40 \\
\hline \multicolumn{7}{|c|}{ Danos Mecânicos (\%) } \\
\hline Amassados & $12,25 b$ & $12,50 \mathrm{~b}$ & $15,75 b$ & $34,50 \mathrm{a}$ & 9,22 & 2,19 \\
\hline Lesões & $4,00 \mathrm{~b}$ & $9,50 \mathrm{ab}$ & $8,00 \mathrm{~b}$ & $16,25 \mathrm{a}$ & 8,08 & 1,92 \\
\hline Esfoladuras & $4,75 b$ & $17,75 \mathrm{a}$ & $3,75 b$ & $25,50 \mathrm{a}$ & 7,88 & 1,87 \\
\hline Cortes & $4,25 b$ & $6,75 b$ & $3,50 \mathrm{~b}$ & $23,75 \mathrm{a}$ & 9,87 & 2,35 \\
\hline \multicolumn{7}{|c|}{ Danos Fisiológicos (\%) } \\
\hline Descolorido & $14,50 \mathrm{ab}$ & $19,75 \mathrm{a}$ & $13,00 \mathrm{ab}$ & $8,25 b$ & 10,00 & 2,38 \\
\hline Talo grosso & $9,50 \mathrm{~b}$ & $10,25 b$ & $9,00 \mathrm{~b}$ & $23,25 \mathrm{a}$ & 6,65 & 1,58 \\
\hline Mal formado & $41,50 \mathrm{~b}$ & $38,75 b$ & $42,75 b$ & $64,00 \mathrm{a}$ & 16,41 & 3,90 \\
\hline Flacidez & $25,00 \mathrm{a}$ & $18,25 b$ & $23,25 \mathrm{ab}$ & $1,75 \mathrm{c}$ & 6,59 & 1,56 \\
\hline Brotado & $9,50 \mathrm{a}$ & $10,50 \mathrm{a}$ & $12,00 \mathrm{a}$ & $2,75 \mathrm{~b}$ & 4,40 & 1,04 \\
\hline \multicolumn{7}{|c|}{ Danos Microbiológicos (\%) } \\
\hline Podridão & $35,50 \mathrm{a}$ & $47,50 \mathrm{a}$ & $35,75 \mathrm{a}$ & $40,00 \mathrm{a}$ & 10,74 & 2,55 \\
\hline Mofado & $64,50 \mathrm{a}$ & $52,50 \mathrm{a}$ & $64,25 \mathrm{a}$ & $60,00 \mathrm{a}$ & 23,84 & 5,76 \\
\hline
\end{tabular}

Médias na linha seguidas de mesma letra minúscula não diferem entre si pelo teste de Tukey a 5\% de probabilidade. DMS: diferença mínima significativa.

Isso evidencia que as cebolas que chegam a rede varejista de Santarém já traz uma elevada carga de danos que certamente se constituirão como causas potenciais de perdas. Almeida et al. (2012a) constataram que injúrias fitopatológicas e o brotamento dos bulbos foram as principais de perdas nas cebolas comercializadas no estado da Paraíba, uma vez que a embalagens utilizadas são sacos de ráfia ou nylon que favorecem corte e injurias que facilitam a contaminação e proliferação de microrganismos.

Todos os pimentões avaliados apresentavam formato retangular e cor verde. Foi inevitável a constatação de danos nos pimentões avaliados, onde nas feiras houve maior incidência destes em relação ao supermercado. Maior quantidade de danos mecânicos se constatou na Feira do Aeroporto Velho, de danos fisiológicos na Feira do Mercadão 2000 e os danos microbiológicos não diferiram entre si para os locais, porém o Supermercado destacou-se quanto aos demais (Tabela 3). Esses resultados assemelham-se aos encontrados por Ribeiro et al. (2011), onde os danos mecânicos provenientes de abrasões tiveram valor expressivo na perda de pimentões. Almeida et al. (2012b) também encontraram que danos mecânicos (amassamento), fisiológicos (amadurecimento, perda de cor, massa e textura) ataque por patógenos foram responsáveis por perdas de $60 \%$ em pimentões comercializados em Areia (PB).

A presença de frutos amassados e apodrecidos não diferiu estatisticamente entre os locais, porém foram mais frequentes na Feira da Cohab. Por outro lado, aqueles com esfoladuras, queimaduras e atacados por insetos forma mais presentes na Feira do Mercadão 2000. Frutos feridos e murchos apresentaram-se em maior quantidade na Feira do Aeroporto Velho, enquanto que no Supermercado foi frequente a presença frutos com rachaduras e mal formados (Tabela 3). Lanna et al. (2006) observaram perdas da ordem de $30 \%$ devido a danos mecânicos oriundos de impactos e compressão nos frutos.

As condições de cultivo de pimentão na região, nas quais os produtores conduzem as plantas a pleno sol, favoreceram a queima e descoloração dos frutos. Além disso, as perdas ocasionadas por desordens fisiológicas aconteceram principalmente pela perda de água e da textura originais, tornando os produtos imprestáveis para o comércio e consumo, devem-se as condições de comercialização e armazenamento com ausência da cadeia de frio, ao longo intervalo de exposição dos frutos no varejo e as elevadas temperaturas da cidade de Santarém. Lanna et al. (2006) constataram que murchamento foi a principal causa de descarte dos frutos de pimentão na rede varejista de Brasília. Para Silva; Giordano (2000), os danos mecânicos, além da perda quantitativa, reduzem a qualidade dos tomates e pimentões, pois os frutos amassados são facilmente contaminados por fungos e bactérias. Lanna et al. (2006) relatam que os principais patógenos comumente identificados como causadores de doenças em frutos de pimentão na etapa 
de pós-colheita são pertencentes às bactérias dos gêneros: Phytophtora sp., Erwinia sp. Colletotrichum sp. Em pimentões comercializados na rede varejista de Viçosa-MG foram observadas que doenças pós-colheita causadas pelos patógenos Erwinia sp. e Colletotrichum sp. ocasionaram perdas de 86,5\% (Marques et al., 2005). Para Lourenzani ;Silva (2004), as altas perdas de hortaliças no varejo podem ser atribuídas, na sua maioria, ao manejo e acondicionamento inadequados, bem como também à classificação e padronização dos produtos insuficientes.

Estes dados mostram que em todos os locais que comercializam hortaliças em Santarém há incidência de danos que são causas de perdas pós-colheita, no entanto nas feiras livres estes foram mais intensos. Podemos atribuir que todos estes danos observados nas hortaliças devem-se ao manuseio excessivo e descuidado com as hortaliças durante a colheita, lavagem, seleção e transporte; uso de embalagens como sacos plásticos ou de ráfia, e engradados de madeira; volume excessivo do produto na embalagem; sobreposição de sacos e caixas durante o transporte; empilhamento inadequado durante a exposição e comercialização. Também as condições climáticas da região com excessiva umidade, favorece os apodrecimentos e a presença de lesões.

Sendo as feiras-livres canais de comercialização muito expressivos no comércio de hortaliças de Santarém, nelas os produtores tem a possibilidade de comercializarem o que produzem e também o que adquirem de outros produtores, porém as hortaliças ali comercializadas apresentaram excessivo volume de danos, o que revela a necessidade de estruturação deste agente de comercialização com a finalidade de reduzir perdas finais e garantir melhores rendimentos aos varejistas. Conforme relataram Vilela et al., (2003a), na rede varejista, os depósitos não oferecem as condições satisfatórias; os funcionários não estão treinados para lidar com as hortaliças, por isso praticam formas incorretas de manuseio, despejando os produtos nas gôndolas sem os cuidados necessários, o que resulta em ferimentos ou amassamentos.

Tabela 3. Classificação dos tipos de danos encontrados em frutos de pimentão comercializados na rede de comércio varejista de Santarém. Pará

\begin{tabular}{|c|c|c|c|c|c|c|}
\hline \multirow[b]{2}{*}{ Variáveis } & \multicolumn{4}{|c|}{ Locais avaliados } & \multirow[b]{2}{*}{ DMS } & \multirow[b]{2}{*}{ Erro } \\
\hline & $\begin{array}{c}\text { Feira da } \\
\text { Cohab }\end{array}$ & $\begin{array}{c}\text { Feira do Mercadão } \\
2000\end{array}$ & $\begin{array}{c}\text { Feira do Aeroporto } \\
\text { Velho }\end{array}$ & $\begin{array}{c}\text { Rede de } \\
\text { Supermercados }\end{array}$ & & \\
\hline \multicolumn{7}{|c|}{ Ausência e presença de danos (\%) } \\
\hline Sem danos & $62,00 \mathrm{c}$ & $65,00 \mathrm{~b}$ & $68,00 \mathrm{a}$ & $70,00 \mathrm{a}$ & 1,90 & 3,80 \\
\hline Com danos & $38,00 \mathrm{a}$ & $35,00 \mathrm{a}$ & $32,00 \mathrm{a}$ & $30,00 \mathrm{~b}$ & 6,30 & 1,90 \\
\hline \multicolumn{7}{|c|}{ Tipos de Danos $(\%)$} \\
\hline Mecânicos & $51,25 \mathrm{a}$ & $39,25 \mathrm{~b}$ & $58,75 a$ & $34,00 \mathrm{~b}$ & 10,57 & 2,51 \\
\hline Fisiológicos & $29,50 \mathrm{ab}$ & $37,25 \mathrm{a}$ & $10,00 \mathrm{~b}$ & $30,75 \mathrm{ab}$ & 27,08 & 6,44 \\
\hline Microbiológicos & $19,25 \mathrm{a}$ & $24,00 \mathrm{a}$ & $31,25 \mathrm{a}$ & $35,25 \mathrm{a}$ & 26,27 & 6,25 \\
\hline \multicolumn{7}{|c|}{ Danos Mecânicos } \\
\hline Amassados & $50,00 \mathrm{a}$ & $36,75 a$ & $45,00 \mathrm{a}$ & $37,50 \mathrm{a}$ & 23,92 & 5,96 \\
\hline Feridos/cortes & $33,25 b c$ & $36,00 \mathrm{c}$ & $52,50 \mathrm{a}$ & $43,75 \mathrm{ab}$ & 19,79 & 4,71 \\
\hline Esfoladuras & $16,75 \mathrm{ab}$ & $27,25 \mathrm{a}$ & $0,00 \mathrm{~b}$ & $16,25 \mathrm{ab}$ & 17,48 & 4,16 \\
\hline \multicolumn{7}{|c|}{ Danos Fisiológicos (\%) } \\
\hline Rachaduras & $1,75 b$ & $4,25 \mathrm{~b}$ & $3,00 \mathrm{~b}$ & $34,75 a$ & 9,62 & 2,29 \\
\hline Queimaduras & $28,50 \mathrm{a}$ & $49,00 \mathrm{a}$ & $25,25 \mathrm{a}$ & $4,50 \mathrm{a}$ & 36,83 & 8,76 \\
\hline Estrias & $30,75 \mathrm{a}$ & $8,75 \mathrm{ab}$ & $10,25 b$ & $34,75 \mathrm{ab}$ & 23,96 & 5,70 \\
\hline Mal formado & $13,00 \mathrm{a}$ & $17,25 \mathrm{a}$ & $6,25 \mathrm{a}$ & $26,00 \mathrm{a}$ & 29,97 & 7,13 \\
\hline Murchas & $32,50 \mathrm{ab}$ & $20,75 b$ & $47,75 \mathrm{a}$ & $0,00 \mathrm{c}$ & 16,84 & 4,01 \\
\hline \multicolumn{7}{|c|}{ Danos Microbiológicos } \\
\hline Apodrecimento & $71,00 \mathrm{a}$ & $57,50 \mathrm{a}$ & $87,00 \mathrm{a}$ & $61,25 \mathrm{a}$ & 43,05 & 10,25 \\
\hline $\begin{array}{l}\text { Ataque por } \\
\text { insetos }\end{array}$ & $29,00 \mathrm{a}$ & $42,50 \mathrm{a}$ & $13,00 \mathrm{a}$ & $38,75 \mathrm{a}$ & 49,52 & 11,79 \\
\hline
\end{tabular}

Médias na linha seguidas de mesma letra minúscula não diferem entre si pelo teste de Tukey a 5\% de probabilidade. DMS: diferença mínima significativa.

\section{CONCLUSÕES}

Existe a necessidade de uma estruturação dos mercados varejistas de Santarém (PA) a fim de promover a redução das indesejáveis perdas e prejuízos financeiros, e ao mesmo tempo proporcionar melhor articulação nos mercados e combater a perda de alimentos, provocando queda na relação volume perdido:comercializado, refletindo na diminuição dos preços ao consumidor final, sem diminuir a lucratividade do varejo.

Ações como evitar as compras excessivas, prevenção contra os efeitos das condições ambientais impróprias, estruturação das condições de armazenamento, melhoras na classificação, padronização na qualidade dos produtos, a adoção de embalagens adequadas e assistência técnica para a orientação dos produtores rurais e proprietários de bancas de como devem armazenar e expor as hortaliças no momento da comercialização, ajudariam muito a reduzir danos potenciais. Também, é importante investir na educação do consumidor final através de campanhas educativas e instrutivas para evitar manuseio inadequado durante a escolha das hortaliças.

\section{AGRADECIMENTOS}

A Rede CR de Supermercados e aos comerciantes das feiras, por gentilmente, nos ter permitido a execução das atividades de pesquisa e coleta de dados em suas 
dependências. Ao CNPq pelo consentimento das bolsas de iniciação científica.

\section{REFERÊNCIAS}

ALMEIDA, E. I. B.; LUCENA, H. H.; RIBEIRO, W. S.; OLIVEIRA, M. R. T.; BARBOSA, J. A. Análise das perdas de caule, folhas e frutos de hortaliças frescas comercializadas na rede varejista de Areia (PB). Revista Brasileira de Agropecuária Sustentável, v. 2, n. 2, p. 81-91, 2012 a.

ALMEIDA, E. I. B.; RIBEIRO, W. S.; COSTA, L. C.; LUCENA, H. H.; BRBOSA, J. A. Levantamento de perdas em hortaliças frescas na rede varejista de Areia (PB). Revista Brasileira de Agropecuária Sustentável (RBAS), v. 2, n. 1, p. 53-60, Julho, 2012b.

CENCI, S. A. Boas Práticas de Pós-colheita de Frutas e Hortaliças na Agricultura Familiar. In: NASCIMENTO NETO F. (Org.). Recomendações Básicas para a Aplicação das Boas Práticas Agropecuárias e de Fabricação na Agricultura Familiar. Brasília: Embrapa Informação Tecnológica, $1^{\text {a }}$ Ed. p. 67-80. 2006.

CHITARRA, M. I. F.; CHITARRA, A. B. Pós-colheita de frutos e hortaliças: fisiologia e manuseio. 2.ed. revisada e ampliada. Lavras: UFLA. 785p. 2005.

FERNANDES, A. M.; SORATTO, R. P.; EVANGELISTA, R. M.; SILVA, B. L.; SOUZASCHLICK, G. D. Produtividade e esverdeamento pós-colheita de tubérculos de cultivares de batata produzidos na safra de inverno. Revista Ciência Agronômica, v. 42, p. 502-508, 2011.

IBGE. INSTITUTO BRASILEIRO DE GEOGRAFIA E ESTATÍSTICA. Censo Agropecuário 2010. Disponível em: http://cidades.ibge.gov.br/xtras/temas.php?lang=\&codmun=1 50680\&idtema $=130 \&$ search $=$ para|santarem/estimativa-dapopulacao-2015-. Acesso em: 17 de outubro de 2016.

LANA, M. M.; MOITA, A. W.; SOUZA, G. S.; NASCIMENTO, E. F.; MELO, M. F. Identificação das causas de perdas pós-colheita de pimentão no varejo. Brasília: Embrapa Hortaliças, 23p. 2006. (Boletim de Pesquisa e Desenvolvimento, 17).

LOURENZANI, A. E. B. S.; SILVA, A. L. Um Estudo da Competitividade dos Diferentes Canais de Distribuição de Hortaliças. Gestão e Produção, v. 11, p. 385-398, 2004.

LUENGO, R. F. A.; HENZ, G. P.; MORETTI, C. L.; CALBO, A. G. Pós-colheita de hortaliças. Brasília: Embrapa Informação Tecnológica. 2007. 100p.

LUENGO, R. F. A.; CALBO, A. G. Pós-colheita de hortaliças: o produtor pergunta, a Embrapa responde. Brasília: Embrapa Informação Tecnológica. 2011. 251p.
MARQUES, L. C. S.; FINGER, F. L.; MENDONÇA, H. L.; GUIMARÃES, A. A. Perdas de pimentão na rede varejista de Viçosa-MG. Horticultura Brasileira, v.23, p.341. 2005. Suplemento.

MELO, P. C. T.; VILELA, N. J. Importância da cadeia produtiva brasileira de hortaliças. Brasília: MAPA. (Palestra apresenta pelo $1^{\circ}$ autor na $13^{\mathrm{a}}$ Reunião Ordinária da Câmara Setorial da Cadeia Produtiva de Hortaliças). 2007.

RIBEIRO, W. S.; ALMEIDA, E. I. B.; COSTA, L. C.; CARNEIRO, G. G.; BARBOSA, J. A. Perdas pós-colheita de pimentão (Capsicum annuum) no mercado atacadista da EMPASA-CG. Tecnologia e Ciência Agropecuária, v. 5, p. 53-56, 2011.

RINALDI, M. M. Perdas pós-colheita devem ser consideradas. Planaltina: Embrapa Cerrados, 2011.

SILVA, A. R.; NECHET, D. Características Climáticas de Alguns Municípios Produtores de Soja do estado do Pará. 2006. In: CONGRESSO BRASILEIRO DE METEOROLOGIA, 14. Anais eletrônicos... 2006. Trabalho completo. Disponível em: http://www.cbmet.com/edicoes.php?pageNum_Recordset_bu sca=4\&totalRows_Recordset_busca=1006\&cgid=14. Acesso em: 10 de Agosto de 2016.

SILVA, J. B. C.; GIORDANO, L. B. Tomate para processamento industrial. Brasília: Embrapa Comunicação para Transferência de Tecnologia/Embrapa Hortaliças. 168p. 2000.

SOARES, A. G. Perdas pós-colheita de frutas e hortaliças. Fórum Agronegócios da UNICAMP - Qualidade e Segurança de Alimentos. Mesa Redonda - Qual o Tamanho do Desperdício. 2009.

SOUZA, V. J. Padronização, Classificação, Rotulagem, Embalagem de Hortaliças (Alface, Banana, Batata, Cebola, Cenoura, Couve-flor, Pepino, Pimentão e Tomate.). Florianopolis: Secretaria de Estado do Desenvolvimento Rural e da Agricultura - Companhia Integrada de Desenvolvimento Agrícola de Santa Catarina. 152p. 2004.

TOFANELLI, M. B. D.; FERNANDES, M. S.; CARRIJO, N. S.; MARTINS FILHO, O. B. Levantamento de perdas em hortaliças frescas na rede varejista de Mineiros. Horticultura Brasileira, v. 27, p. 116-120, 2009.

VILELA, N. J.; LANA, M. M.; MAKISHIMA, N. O peso da perda de alimentos para a sociedade: o caso das hortaliças. Horticultura Brasileira, v. 21, p. 141-143, 2003 a.

VILELA, N. J.; LANA, M. M.; NASCIMENTO, E. F.; MAKISHIMA, N. Perdas na comercialização de hortaliças em uma rede varejista do Distrito Federal. Cadernos de Ciência e Tecnologia, v. 20, p. 521-541, 2003 b. 